\title{
Anja Dobler-Mikola
}

European Addiction Research Award 1997

The 1997 award of European Addiction Research (EAR) went to a Finnish Social Scientist, Anja Dobler-Mikola, now working at the Addiction Research Institute in Zurich, being proposed by Board Members.

Anja Dobler-Mikola, born 1948, has a long-standing research career in psychiatric epidemiology and in the addiction field. 1979 until 1986 she participated as a senior researcher in the Zurich study at the research department of the Psychiatric University Hospital in Zurich under Prof. J. Angst. After two years as Project Manager in an Information Centre, she returned to the Psychiatric University Hospital as a senior researcher in the department for social psychiatry. Since 1995, she is research director and member of the Management Board at the Addiction Research Institute.

Anja Dobler-Mikola engaged in research projects on suicide, on depressions, on life events, on social networks, on health behaviour and especially on drugs and Aids where she always had a focus on gender issues and adolescence. Her major merits are her contributions to large studies such as the Zurich study, national studies on the career of heroin addicts and especially on psychosocial aspects of HIV. She has implemented a nation-wide documentation and evaluation system for residential drug-free treatment programmes and she is directing the national study on the prescription of narcotics.

Anja Dobler-Mikola has an outstanding ability to implement multi-disciplinary research projects, to engage professionals from treatment institutions into a research network and to foster numerous research initiatives as a consultant. She receives the EAR Award for her many and outstanding contributions to systematic evaluation research.

A. Uchtenhagen Chair of the Award Board KAHGER

Fax + 41613061234 E-Mail karger@karger.ch www. karger. com (C)1997S. KargerAG, Basel 